[Short Communication]

\section{First Description of the female of Stiphropus falciformus (Araneae: Thomisidae)}

\author{
Zong-Xu Li ${ }^{1}$, Yu-Feng Zhou ${ }^{2} \&$ Zi-Zhong Yang ${ }^{1 *}$ \\ ${ }^{1}$ College of Life Science and Chemistry, Dali University, Dali, \\ Yunnan 671000, China \\ ${ }^{2}$ Guizhou Institute of Prataculture, Dushan, Guizhou 558200, \\ China \\ *yangzzh@yahoo.com.cn (corresponding author)
}

\begin{abstract}
The female of Stiphropus falciformus (Yang, Zhu \& Song, 2006) is described and is illustrated for the first time.
\end{abstract}

Key words - Araneae, Thomisidae, Stiphropus.

The genus Stiphropus is a poorly known crab-spider, and recognized due to its thick body and the furcate hairs on the femur, patella, tibia, metatarsus and tarsus. Up to now, 20 species of the genus Stiphropus are described worldly. Its distributional range mostly includes South Africa and Southeast Asia (Platnick 2008). 2 species were recorded from China so far (Yang, Zhu \& Song 2006; Zhu \& Shan 2007).

While we studied the spider specimens collected from Yunnan (Dali, Yuanmou) and Guizhou (Dushan) in the recent years, we discovered the female of Stiphropus falciformus (Yang, Zhu \& Song 2006).

The photo was taken under the stereoscopic Zoom Microscope SMZ1000, and other illustrations were made the XTL II compound microscope equipped with an Abbe drawing device. The measurements of legs are as follow: total length (femur, patella plus tibia, metatarsus, tarsus). The specimens examined are deposited in the College of Life Science and Chemistry, Dali University (CDLC). All measurements given were in millimeters.

\section{Stiphropus falciformus Yang, Zhu \& Song, 2006}

(Figs. 1-5)

Stiphropus falciformus Yang, Zhu \& Song 2006, 65, f. 1A-D.

Diagnosis. Female of Stiphropus falciformus Yang, Zhu \& Song, 2006 resembles S. ocellatus Thorell, 1887 (cf. Zhu \& Shan 2007: 913, f. 1-5), but can be distinguished by the combination of the following characters: anterior margins of epigynum with some fan-shaped folds (Fig. 2) rather than circular; internal ducts without posterior lateral humps in the windings of internal duct system in dorsal view (Fig. 3).

Description of a female. Body length 5.12-5.47. A female length 5.12: prosoma 1.89 long, 1.77 wide; opisthosoma 3.23 long, 2.98 wide. Carapace brown. Eyes diameter: AME 0.09, ALE 0.12, PME 0.05, PLE 0.12. Distance between eyes: AME-AME 0.13, AME-ALE 0.29, ALE-PLE 0.24, PME-PME 0.27, PME-PLE 0.40. MOA anterior width 0.31 , posterior width 0.37 . Clypeus height 0.12 . Chelicerae dark brown, with few small promarginal denticles. Maxillae and labium brown, both longer than wide. Sternum brown, with many short setae. Leg I and II dark brown, III and IV brown, the femora with less furcate hairs than in patellae, tibiae, metatarsi and tarsi. Tarsi longer than metatarsi. Measurements of legs: I 3.28 (0.81, $1.02,0.52,0.92)$; II 4.79(1.27, 1.49, 0.67, 1.37); III 2.72 (0.82, 0.95, 0.38, 0.57); IV $2.86(0.90,0.94,0.42,0.61)$. Leg formula: 2143. Anterior margins of epigynum with some fan-shaped folds, internal ducts appearing as diagonally oriented irregular oviform patches (ventral view), without posterior lateral humps in the windings of internal duct system (dorsal view).

Material examined. 1male, 3 females, Grass Industry Research Institute, Dushan County, Qiannan Prefecture, Guizhou Province, 3 August 2007, collected by Zai-Hua, Yang.

Distribution. Guizhou (Qiannan, Dushan) and Yunnan (Dali, Yuanmou)

\section{References}

Ono, H. 1980. Thomisidae aus dem Nepal-Himalaya. III. Das Genus Stiphropus Gerstaecker 1873, mit Revision der asiatischen Arten (Arachnida: Araneae). Senckenbergiana biology, 61: 57-76.

Ono, H. 2001. Crab spiders of the family Thomisidae from the Kingdom of Bhutan (Arachnida, Araneae). Entomologia Basiliensia, 23: 203-236.

Platnick, N. I. 2009. The world spider catalog, version 9.5. American Museum of Natural History, online at http://research.amnh org/entomology/spiders/catalog/index.html. (Accessed 2 Feb. 2009)

Song, D. X. \& Chai, J. Y. 1990. Notes of some species of the family Thomisidae (Arachnida: Araneae) from Wuling Shan area. In Zhao, E. M. (ed.), From Water onto Land. C.S.S.A.R., Beijing, 364374.

Song, D. X., Zhu, M. S. \& Chen, J. 1999. The Spiders of China. Hebei Science and Technology Publishing House, Shijiazhuang, $640 \mathrm{pp}$.

Yang. Z. Z. Zhu, M. S. \& Song, D. X. 2006. A newly recorded genus from China and two new species of the family Thomisidae (Arachnida Araneae). Acta Arachnol. Sin., 15: 65-69.

Zhu. M. S. \& Shan. Y. J. The new discovery of the female spider Stiphropus ocellatus Thorell, 1887 from China (Araneae: Thomisidae). Acta Zootaxo. Sin., 32: 913-914.

Received March 12, 2009 / Accepted September 12, 2009 

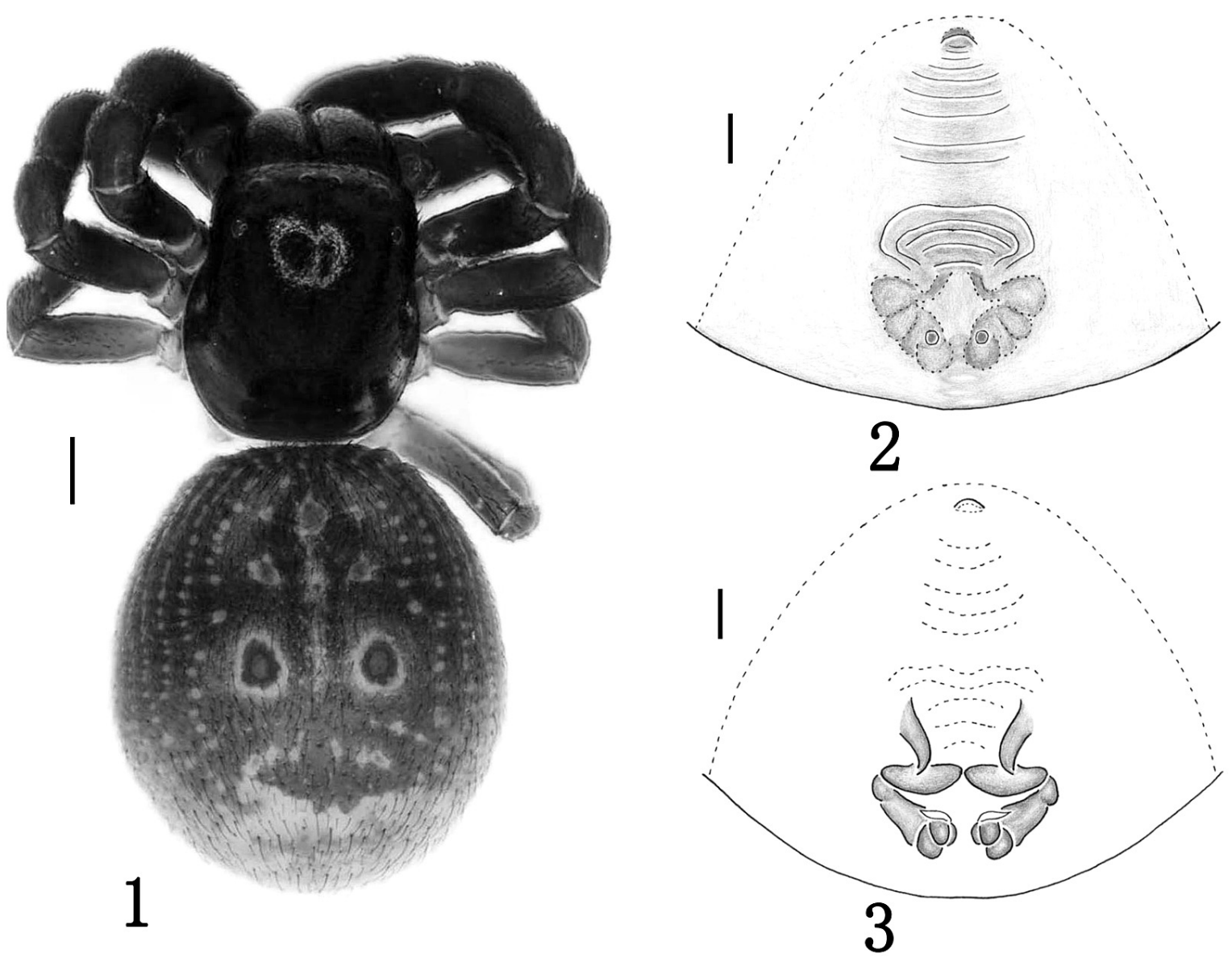

Figs. 1-3. Stiphropus falciformus Yang, Zhu \& Song, 2006. 1. Female body, dorsal view. 2-3, Epigynum: 2, ventral view; 3, dorsal view. (Scales for Fig. 1, $0.5 \mathrm{~mm}$; for Figs. 2-3, $0.1 \mathrm{~mm}$.) 